\title{
Standardization for Mastering Healthcare Transformation - Challenges and Solutions
}

\author{
Bernd Blobel $\left.\right|^{1,2,3,4}$ \\ ${ }^{1}$ Medical Faculty, University of Regensburg, Germany \\ ${ }^{2}$ eHealth Competence Center Bavaria, Deggendorf Institute of Technology, Germany \\ ${ }^{3}$ HL7 Germany, Cologne, Germany \\ ${ }^{4}$ First Medical Faculty, Charles University Prague, Czech Republic
}

\begin{abstract}
Background: The ongoing healthcare transformation results in systems medicine and personalized care. This requires advanced interoperability scenarios.

Objectives: The paper aims at introducing a reference architecture model to enable the harmonization of existing and future specifications and standards.

Methods: For enabling the harmonization of standards and specifications, they have to be correctly and formally represented using a system-theoretical, architecture-centric, ontology-based, policy-driven approach.

Results: An Interoperability Reference Architecture Model has been developed and standardized at ISO TC 215 and CEN TC 251. It is used for re-engineering specifications and standards, that way enabling harmonization with any other specification.
\end{abstract}

\section{Correspondence to:}

Prof. Dr. habil. Bernd Blobel, FACMI, FACHI, FHL7, FEFMI, MIAHSI Medical Faculty, University of Regensburg, Germany

E-mail: bernd.blobel@klinik.uni-regensburg.de
The proposed modeling methodology has also been introduced in several HL7 specifications. It is demonstrated by re-engineering the ISO 13606 reference model.

Conclusion: The approach presented in the paper offers a solution for comprehensive interoperability at any interoperability level also including user domains and the individual user. That way, never-ending revision cycles and negotiation rounds for integrating different specifications in complex eHealth solutions become obsolete.

\section{Keywords}

Healthcare transformation; Interoperability; Reference architecture model; Systems theory; Ontology; Policy

EJBI 2017; 13(1):09-15

received: July 24,2017

accepted: August 15, 2017

published: October 10, 2017

\section{Introduction}

Healthcare transformation, translational medicine - what's behind those terms and related moves? Health systems around the world are faced with the demographic change towards aging, multi-diseased societies, the related development of human resources, a demanding attitude regarding health and social services, and medical and biomedical progress, altogether bound to exploding costs for health-related R\&D as well as health services delivery.

The first approach for managing the aforementioned challenges by healthcare transformation goes back to Kaiser Permanente's pioneering efforts of "inventing" managed care in the early twenties of the last century. In the seventies this approach of controlling health services delivery and financing in a system under medical and economic aspects with a special focus on process efficiency and efficacy for cost containment has been generalized in the US and implemented in so-called Health Maintenance Organizations (HMOs). A specialty in the context of chronic and/or multi-morbid patients is disease management or case management. Meanwhile, many different managed care concepts have been implemented in different regions around the world [1].

The next level of healthcare transformation focuses stronger on quality and outcome of the care process, resulting in value-based medicine. When measuring health outcome as part of care delivery, clinical practice and life sciences research get aligned [2]. Developing and implementing better prevention, new diagnostic tools and treatments by using a multi-disciplinary, highly collaborative, 'from bench-to-bedside' approach is called translational medicine [3]. Population health supports spreading those achievements throughout the community, so completing 
the three pillars 'bench-side', 'bed-side', and 'community' of translational medicine. The convergence of healthcare and life sciences ecosystems leads to personalized healthcare. The transformation of health systems is combined with a changing definition of health from a status free of diseases towards physical, psychological and social wellbeing. The aforementioned demographic, social and economic challenges lead to health systems paradigm changes. Following, the health systems evolution from the perspective of interoperability will be considered in some more details.

\section{The Transformation of the Healthcare Eco- System - A System-Theoretical Approach}

As discussed in several papers already $[4,5,6]$, the health systems paradigm changes we are facing can be grouped in three dimensions: organizational, methodological, and technological. Organizationally, healthcare delivery turns from organization-centric through process controlled (DMP) to person-centered systems. In methodological respect, health services delivery was traditionally performed as an empirical, phenomenological approach to general care addressing health problems by one solution fits all. At next level, population was stratified according to specific clinical conditions for an evidence-based approach to dedicated care. Finally, we move towards personalized, preventive, predictive and participative care considering individual health state, conditions and contexts, i.e. a systems medicine approach from art to multi-disciplinary science. Technologically, a move to fully distributed systems, mobile technologies, nano, molecular and bio-technologies, knowledge representation \& -management, artificial intelligence, big data \& business analytics, cloud computing, and social business happens.

For properly modeling the described health systems evolution, we will deploy systems theory for representing, analyzing and designing the systems in question [7].

A system is an ordered composition of interrelated elements, which have properties in common distinguishing them from those elements defining the system's environment. A system interacts with its environment. A system represents constructive or structural aspects on the one side and functional aspects on the other side. Considering just phenomena observed, the system's function as a black box can be described by the transformation of inputs into specific outputs under special environmental impacts. The quality of inputs and outputs can belong to the following categories: material, energy, and information. A system's architecture describes the system's elements (components), their functions and their interrelations. A system can be considered from different perspectives - the system's domains - usually performed by domain experts using their methodologies, terminologies and underlying ontologies.
Examples are the medical, legal, or administrative perspective on health systems. The representation of specific perspectives on a real world system - the system's domains - has to be based on those domains' ontologies. An ontology describes an ordering system of entities of a domain and their relations. After Gruber, an ontology is a formal explicit specification of a shared conceptualization of a domain of interest [8]. Rules for selecting components and functions as well as constraints of the relations according to a business case are called policies. Policies define the intended behavior of a system.

The organizational and the methodological paradigm changes health systems are faced with result in higher structural complexity of those systems. Transformative healthcare systems are represented by the subject of care and the processes analyzing and managing his/her health comprises all levels of granularity from atoms through molecules, cell components, cells, tissues, organs, bodies, communities, up to population. Regarding the functional, or in general inter-relational, aspects of that system, the number of perspectives or domains to be included increases, comprising quantum-mechanical effects in the nano-world, biochemical processes, interrelations based on classical physics, and finally social interrelations in the macro-world. We have to have always in mind: As we can consistently model and compute only systems of reasonable complexity, the system analysis or design has to address partial systems when considering higher granularity levels of the system in question.

Health systems transformation leads regarding its structure to fine grained, more complex systems, and regarding its functions and interrelations to dynamic, multidomain (multidisciplinary) systems.

\section{The Transformative Healthcare Interoperabili- ty Challenge}

Interoperability is traditionally considered according to the IEEE definition as "ability of two or more systems or components to exchange information and to use the information that has been exchanged" [9]. It has been implemented as communication at the level of data/ information exchange such as structured messaging (e.g. EDI (Electronic Data Interchange), HL7 messaging) or sharing concepts (e.g. openEHR Archetypes [10], ISO 13940 ContSys concepts [11]), and as cooperation at application level (e.g. Web services, such as HL7 FHIR Resources (Fast Healthcare Interoperability Resources) [12]).

The described interoperability levels are gray shadowed in Figure 1 [13], representing different levels of data/ information sharing or application services provision. For such interoperability approaches, the quality of inputs and outputs of the systems considered is limited to information, and the perspective and representation style is just ICT and its 


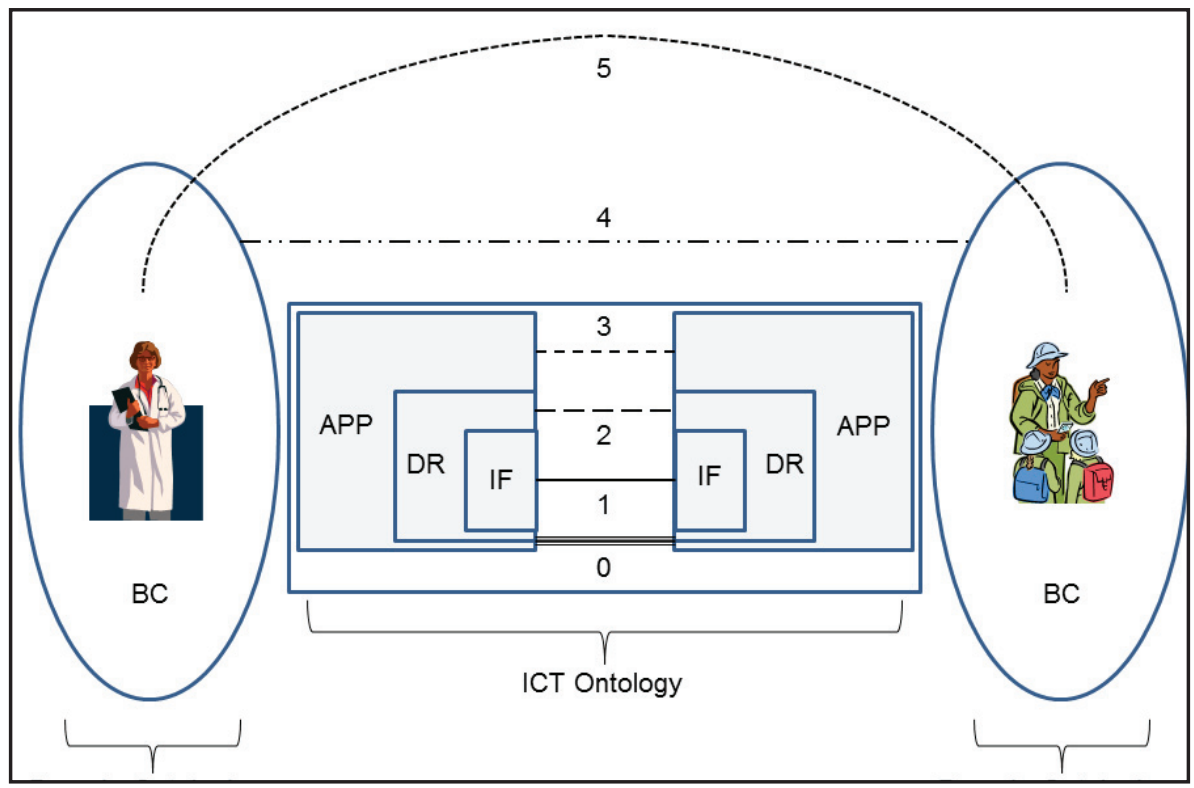

Figure 1: Interoperability schema [13].

ontologies, more or less ignoring the domains (disciplines) to be supported, their knowledge and methodologies expressed in their concepts as elements of their ontologies.

However, this is not the only limitation of the traditional interoperability approach. The definition and representation of concepts depends on the involved domains, the concrete business case, the business objectives, the business as well as the individual context, the selected business process for meeting the business objectives. For establishing advanced interoperability, all those conditions defining communication and cooperation between entities must be mutually considered. In detail, this implies in a white box approach the definition of the system to be considered for the business case and the intended business objectives, i.e. the components, functions and interrelations as system's architecture needed, but also related environmental and contextual conditions. The implicit knowledge on the defined system and its behavior provided by domain experts must be represented explicitly for enabling the performance of cooperative decisions on the systems required architecture and processes. So, advanced interoperability requires a system-theoretical, architecture-centric, ontology-based approach. The aforementioned interoperability decisions on the system in question can only be provided at that real-world level, but not at the level of its informational representation necessary for its implementation. In other words, the non-ICT interoperability is not just defining the ICT interoperability solution, it is the real challenge in the game.

As in detail discussed in [14] already, it is not just the complexity caused by multiple disciplines, but also the involvement of differently qualified actors merging different professions, but also professionals and laymen. The subject of care, frequently a layman in the healthcare business, is in the center and dominates or even controls the process. For that purpose, all interoperability levels presented in Table 1 must be provided by all participating systems cooperating on this level.
Organizational, methodological and technological paradigm changes in health systems require a multidisciplinary, international and even global approach in legal, cultural, language, terminology and ontology respect. This requires the management of multiple domains including multiple policy domains as presented in Figure 2 [14].

Table 1: Interoperability levels of the comprehensive interoperability schema.

\begin{tabular}{|c|c|c|c|}
\hline \multicolumn{2}{|c|}{ Information Perspective } & \multicolumn{2}{|l|}{$\begin{array}{l}\text { Organizational } \\
\text { Perspective }\end{array}$} \\
\hline $\begin{array}{l}\text { Interoperability } \\
\text { Level }\end{array}$ & Instances & $\begin{array}{l}\text { Interoperability } \\
\text { Level }\end{array}$ & \\
\hline $\begin{array}{l}\text { Technical } \\
\text { interoperability }\end{array}$ & $\begin{array}{l}\text { Technical plug } \\
\text { \& play, signal- } \\
\text { \& protocol } \\
\text { compatibility }\end{array}$ & $\begin{array}{l}\text { Light-weight } \\
\text { interactions }\end{array}$ & Simple \\
\hline $\begin{array}{l}\text { Structural } \\
\text { interoperability }\end{array}$ & $\begin{array}{l}\text { Simple EDI, } \\
\text { envelopes }\end{array}$ & $\begin{array}{l}\text { Information } \\
\text { sharing }\end{array}$ & $\mathrm{T}$ \\
\hline $\begin{array}{l}\text { Syntactic } \\
\text { interoperability }\end{array}$ & $\begin{array}{l}\text { Messages and } \\
\text { clinical documents } \\
\text { with agreed upon } \\
\text { vocabulary }\end{array}$ & & \\
\hline $\begin{array}{l}\text { Semantic } \\
\text { interoperability }\end{array}$ & $\begin{array}{l}\text { Advanced } \\
\text { messaging } \\
\text { with common } \\
\text { information models } \\
\text { and terminologies }\end{array}$ & Coordination & $\Uparrow$ \\
\hline $\begin{array}{l}\text { Organizations/ } \\
\text { Service } \\
\text { interoperability }\end{array}$ & $\begin{array}{l}\text { Common business } \\
\text { process }\end{array}$ & $\begin{array}{l}\text { Agreed } \\
\text { Cooperation }\end{array}$ & \\
\hline $\begin{array}{l}\text { Knowledge- } \\
\text { based } \\
\text { interoperability }\end{array}$ & $\begin{array}{l}\text { Multi-domain } \\
\text { processes }\end{array}$ & $\begin{array}{l}\text { Cross-domain } \\
\text { Cooperation }\end{array}$ & \\
\hline $\begin{array}{l}\text { Skills-based } \\
\text { interoperability }\end{array}$ & $\begin{array}{l}\text { Multi-domain } \\
\text { individual } \\
\text { engagement }\end{array}$ & $\begin{array}{l}\text { Moderated } \\
\text { end-user } \\
\text { collaboration }\end{array}$ & Advanced \\
\hline
\end{tabular}




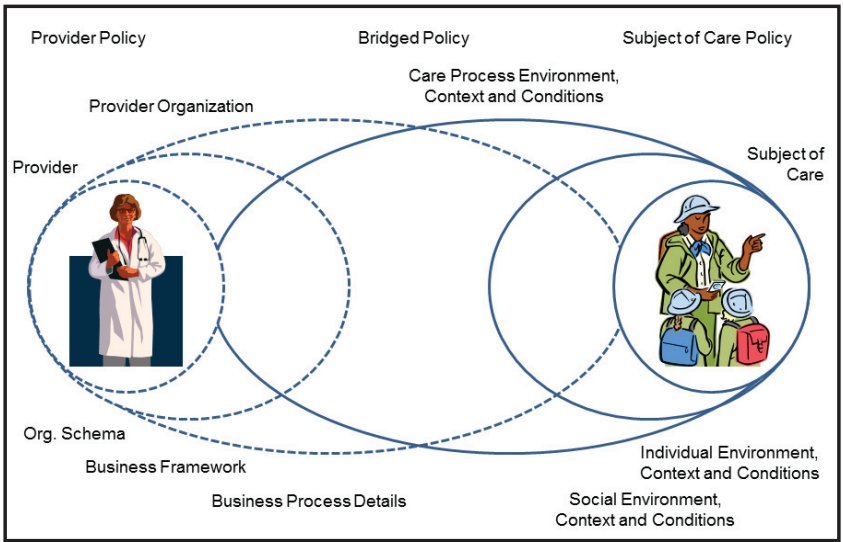

Figure 2: pHealth interoperability schema [14].

\section{The Interoperability Reference Architecture Model Standard}

Standards Development Organizations (SDOs) claim to enable open and flexible cooperation between actors in health business cases while usually addressing a specific aspect of the business from a specific domain's perspective. At best, they thereby deploy (somehow) that domain's ontology. In real world business systems and especially in the context of advanced healthcare paradigms however, multiple domains are involved.

For meeting the multi-disciplinary interoperability challenges, an abstract domain-independent representation of systems is deployed, based on a system-theoretical, architecture-centric, ontology-driven approach explained above $[4,6]$. The mathematical concept representation using the universal type theory in combination with systems engineering methodologies allows representing any system architecturally (i.e. the system's components, their functions and internal as well as external relations) by generically describing its composition/decomposition as well as the aspects (domains) of the system relevant in a specific context (e.g. business case), instantiated using those

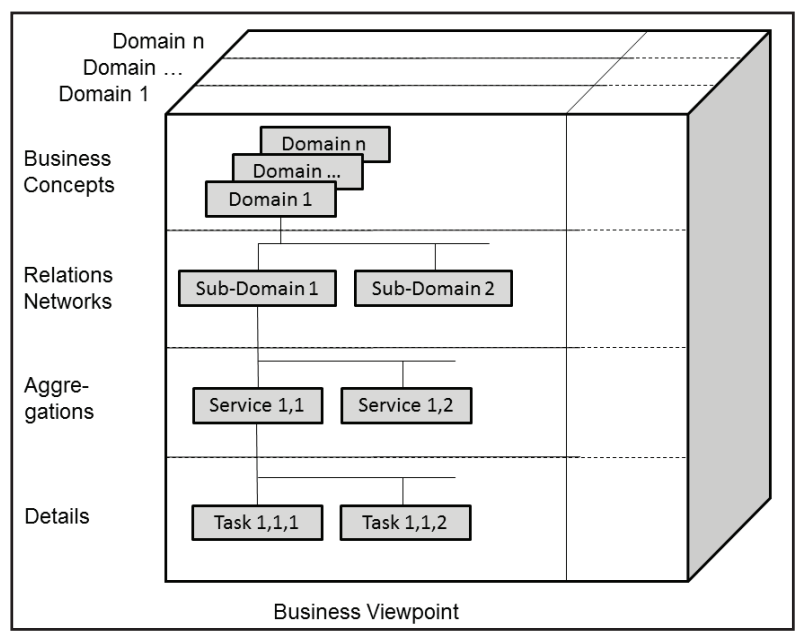

Figure 3: Granularity Levels of the Interoperability Reference Architecture Model. domains' ontologies. The reference architecture model - here focusing on the business domain - can be used recursively, so representing, e.g., the real-world systems' continuum from elementary particles to the universe (Figure 3).

Additionally to agreeing on one or more, and at best standards-based, ICT ontologies, the agreed domains' knowledge, but also individual (language, education, skills, experiences, social and psychological aspects, etc.) and environmental context must be represented, harmonized and communicated by instantiating the system's architectural components and behavior through the domain-specific ontologies and policies.

By combining that model with ISO/IEC 10746 RMODP, the Interoperability Reference Architecture Model (introduced in the nineties as Generic Component Model GCM) as well as the applicable rules - the Interoperability Reference Architecture Model Framework - (also known as GCM Framework) is completed (Figure 4) $[6,15]$.

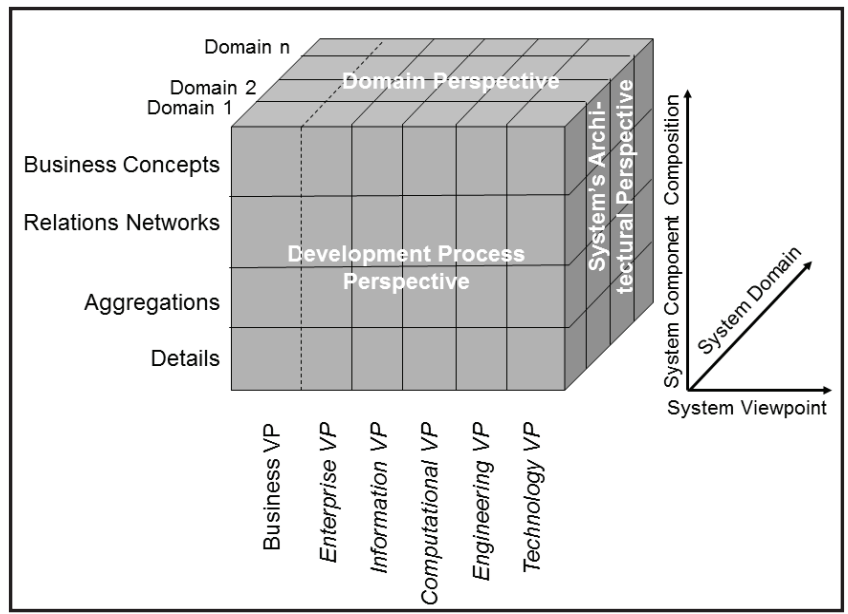

Figure 4: The interoperability reference architecture model.

This Interoperability Reference Architecture Model allows consistently transforming and interrelating any domainspecific subsystem's structure and behavior (e.g. domainspecific standards and specifications) by ontologically representing its concepts and relationships at the real world system component's level of granularity. In other words, the domain-specific subsystem (e.g. a domain-specific standard or specification) is re-engineered using the Interoperability Reference Architecture Model, by that way providing a standardized interface to that specification (Figure 5).

According to the GCM Framework, inter-domain relationships can only be established at the same level of granularity [16]. Therefore, intra-domain specializations/ generalizations have to be performed first.

ISO TC 215 "Health informatics" and CEN TC 251 "Health informatics" decided at the Joint Working Group Meeting 2015 in Bern, Switzerland, already to follow the presented approach for all interoperability specifications. The solution has meanwhile been standardized at ISO 
TC 215. The Interoperability Reference Architecture Model supports ontology harmonization or knowledge harmonization to enable interoperability between existing systems, standards and solutions of any level of complexity without the demand for continuously adapting/revising those specifications.

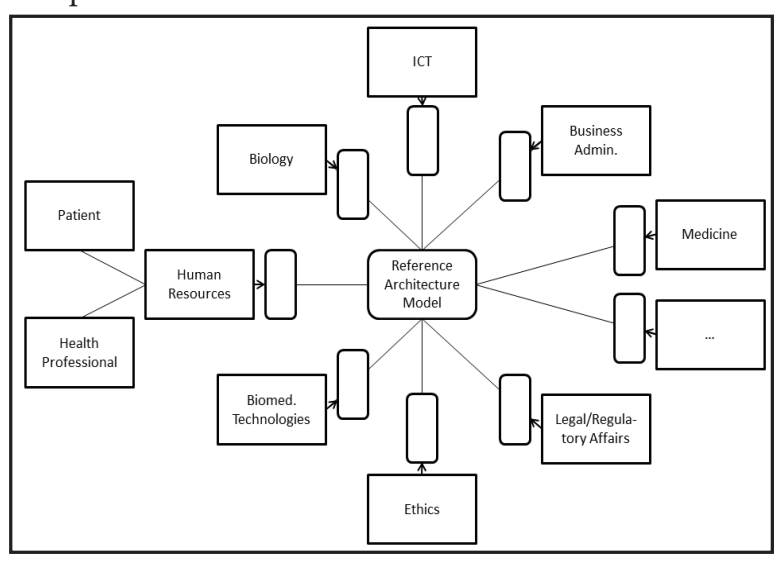

Figure 5: Interoperability mediated by the interoperability reference architecture model.

\section{Example for Re-Engineering an ISO}

\section{Specification Using the Interoperability Reference}

\section{Architecture Model}

A basic ISO standard, endlessly revised for adopting to, and interconnecting with, many related specifications, is ISO 13606 "Health informatics - EHR communication" [10]. Therefore, its conceptual model (ISO 13606 Reference Architecture) has been re-engineered to enable advanced interoperability to any other specification. Figure 6 presents the ISO 13606 Reference Architecture Model.

As an example, Figure 7 presents the outcome of reengineering the ISO 13606 "EHR communication" Reference Model (colored components) into the GCM, thereby just considering the domains addressed in that model. On that basis, the harmonization of ISO 13606 with other specs such as ISO 22600 Health informatics - Privilege management and access control [17], ISO 21298 Health informatics - Functional and structural roles [18], - a permanent challenge Standards Development Organizations are faced with - can be easily performed. The Figure 7 shows a mixture of different viewpoints requiring advanced transformations not considered in the standard. Furthermore, there is a vast amount of explicit knowledge missing in ISO 13606 but necessary for harmonization as demonstrated by the non-colored components, which complete the architectural model. Just the ISO 13606 components presented in three dimensions represent valid architectural components in the reference architecture model. The others (colored rectangles) have to be transferred into valid components.

The described process can be automated. The same holds for transforming the cross-domain, harmonized, consistent informational representation of the complex business system into the different ISO/IEC 10746 views [19] for analyzing,

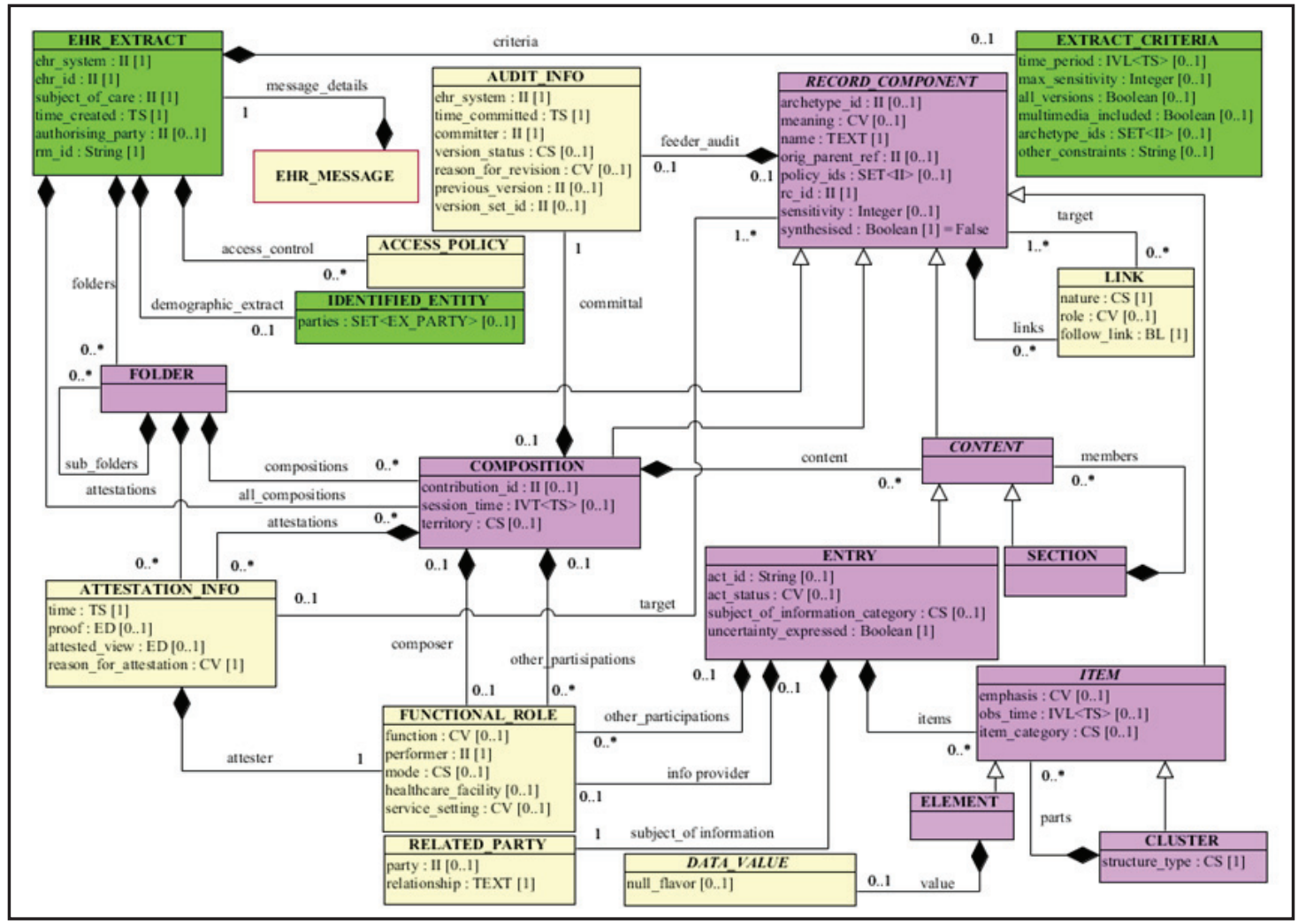

Figure 6: ISO 13606 reference Model. 


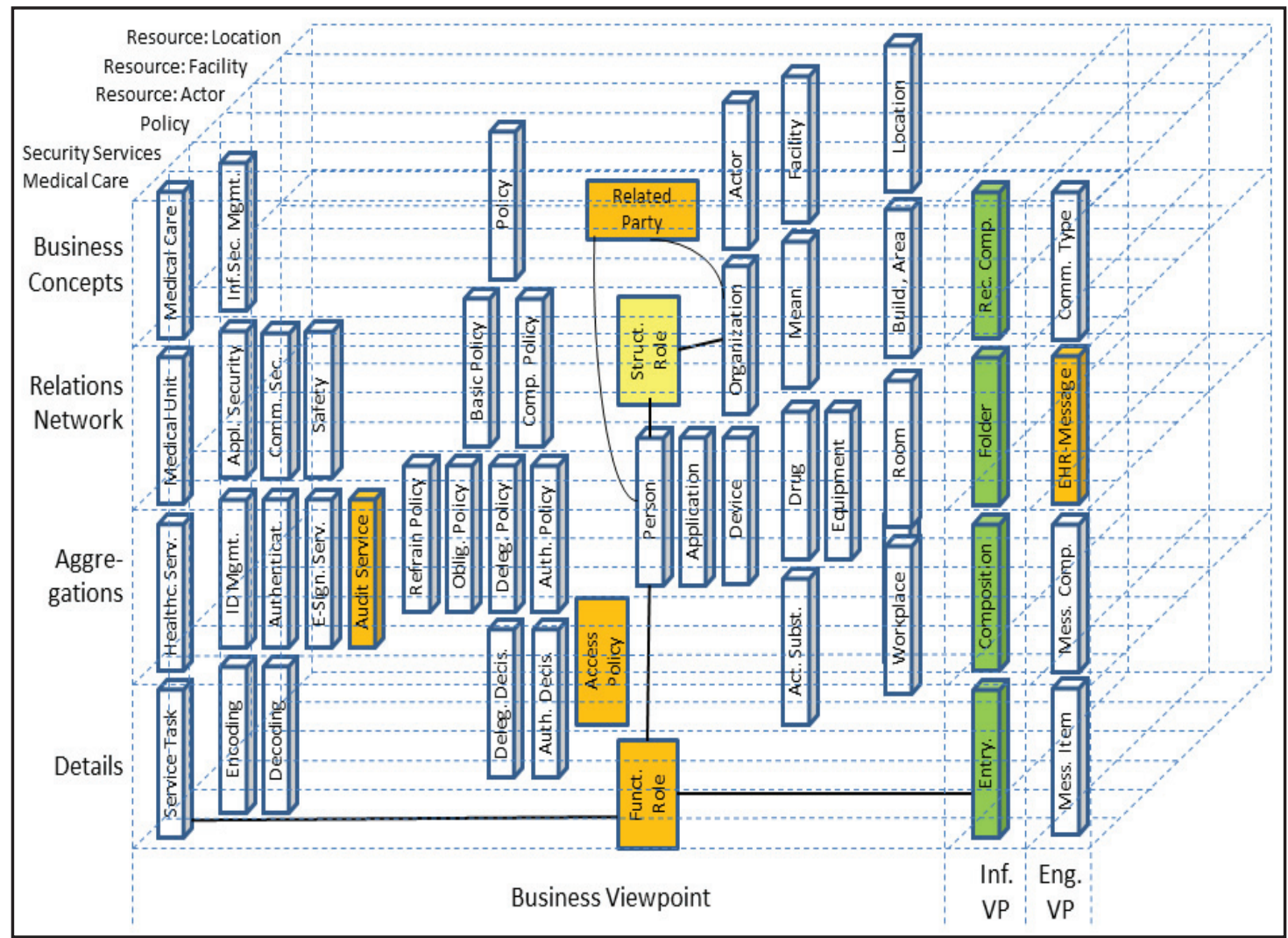

Figure 7: Re-engineering example of the ISO 13606 reference Model.

designing, implementing and maintaining the related ICT solution.

\section{Discussion and Conclusion}

For harmonizing domain or use case specific specifications when adding a new specification or changing/ extending the business case, especially when including another domain, currently a mutual adaptation and harmonization is performed, resulting in a revision process of the impacted standards and specifications. With increasing complexity and variability of the system and the diversity of its subsystems and components, the lifetime of domain specific specifications goes down, and a comprehensive precoordination is impossible.

The alternative way of a priori harmonizing the aforementioned highly complex, highly dynamic, multidisciplinary/multi-domain advanced healthcare system by representing it by one domain's terminology/ontology or even worse - by using ICT ontologies fails. The same holds when using one domain's representational style and models or standards as reference or master that all other domains and their experts must adhere to, e.g., by enforcing biologists, physicians, philosophers and artists to think and represent in UML and the 78 concepts of the ICT base ontology [20].

Therefore, an adaptive approach is required to sharing and harmonizing ICT, domain, and personal ontologies and conditions at runtime.
The presented approach has been successfully deployed in several cross-domain ISO specifications, such as ISO 22600, ISO 21298, HL7 Composite Security and Privacy Domain Analysis Model [21]. Its feasibility has been practically demonstrated for automatically harmonizing HL7 v2.x and HL7 v3 specifications [16, 22], for enabling use case and domain crossing interoperability in the context of ISO 13972 Health informatics - Detailed clinical models [23, 24], or for automatically designing inter-domain Web services to facilitate multi-disciplinary approaches to Type 2 Diabetes Care management $[25,26]$. The approach also allows a comparative analysis and evaluation of ICT Enterprise Architectures [6].

The increasingly complex interoperability challenge cannot be met starting from an information object point of view, as most of the existing approaches including many HL7 work products do. When constructing a picture of the real world from those information artefacts, we will result in the tragic situation of creating an excellent map, however the landscape is wrong.

\section{Acknowledgements}

The author is indebted to thank his colleagues from ISO TC 215, CEN TC 251, and HL7 International for their kind cooperation and support. 


\section{References}

[1] Amelung VE, Krauth C, Mühlbacher A. Managed Care. Springer: Gabler Wirtschaftslexikon. http://wirtschaftslexikon.gabler.de/

[2] Hansson E, Spencer B, Kent J, Clawson J, Meerkatt H, Lanson S. The Value-Based Hospital and Translational Medicine. Bcg.perspectives, September 09, 2014. https://www.bcgperspectives.com/content/articles/ health_care_payers_providers_transformation_large_scale_change_ value_based_hospital_translational_medicine/

[3] Wikipedia. Translational medicine. https://en.wikipedia.org/wiki/ Translational_medicine

[4] Blobel B. Architectural Approach to eHealth for Enabling Paradigm Changes in Health. Methods Inf Med. 2010; 49: 123-134.

[5] Blobel B. Translational Medicine Meets New Technologies for Enabling Personalized Care. Stud Heaqlth Technol Inform. 2013; 189: 8-23.

[6] Blobel B, Oemig F. The Importance of Architectures for Interoperability. Stud Health Technol Inform. 2015; 211: 18-56.

[7] Völz H. Information. Berlin: Akademie-Verlag; 1982.

[8] Gruber TR. Toward principles for the design of ontologies used for knowledge sharing. Int J Human - Computer Studies. 1995; 43: 907-928.

[9] IEEE Standard Computer Dictionary: A Compilation of IEEE Standard Computer Glossaries, IEEE; 1990.

[10] International Organization for Standardization. ISO 13606:2017 Health informatics - EHR communication. Geneva: ISO; 2017.

[11] International Organization for Standardization. 13940:2015 Health informatics - System of concepts to support continuity of care. Geneva: ISO; 2015.

[12] Health Level 7 International, Inc. Fast Health Interoperability Resources (FHIR). Available at http://www.hl7.org.

[13] Oemig F and Blobel B. Natural Language Processing Supporting Interoperability in Healthcare. In: Biemann C, Mehler A (Edrs.) Text Mining - From Ontology Learning to Automated Text Processing Applications, 137-156. Series Theory and Applications of Natural Language Processing. Heidelberg: Springer-Verlag GmbH; 2014.
[14] Blobel B, Ruotsalainen P, Lopez DM, Oemig F (2017) Requirements and Solutions for Personalized Health Systems. Stud Health Technol Inform. 2017; 237: 3-21.

[15] Oemig F. Development of an ontology-based architecture for ensuring semantic interoperability between communication standards in healthcare (in German). PhD Thesis, University of Regensburg, Medical Faculty, Regensburg, Germany, 2011.

[16] Oemig F, Blobel B. A Formal Analysis of HL7 Version 2.x. Stud. Health Technol Inform. 2011; 169: 704-708.

[17] International Organization for Standardization. ISO 22600:2014 Health informatics - Privilege management and access control. Geneva: ISO; 2014.

[18] International Organization for Standardization. ISO 21298:2016 Health informatics - Structural and functional roles. Geneva: ISO; 2016.

[19] International Organization for Standardization. ISO/IEC 10746-2:1996 Information Technology - Open Distributed Processing - Reference Model: Foundations. Geneva: ISO; 1996.

[20] Akerman A, Tyree J. Using ontology to support development of software architectures. IBM Systems Journal. 2006; 45: 813-825.

[21] Health Level 7 International, Inc. HL7 Composite Security and Privacy Domain Analysis Model. Available at http://www.hl7.org.

[22] Oemig F, Blobel B. A Communication Standards Ontology Using Basic Formal Ontologies. Stud Health Technol Inform. 2010; 156: 105-113.

[23] Goossen WTF. Detailed clinical models: Representing knowledge, data and semantics in healthcare information technology. Healthcare Informatics Research. 2014; 20: 163-172.

[24] Goossen W, Gossen-Baremany A, Van Der Zel M. Detailed clinical models: A review. Healthcare Informatics Research. 2010; 16: 201-2014.

[25] Uribe GA, Blobel B, López DM, Schulz S. A Generic Architecture for an Adaptive, Interoperable and Intelligent Type 2 Diabetes Mellitus Care System. Stud Health Technol Inform. 2015; 211: 121-131.

[26] Uribe GA, Blobel B, López DM, Ruiz AA. Specializing Architectures for the Type 2 Diabetes Mellitus Care Use Cases with a Focus on Process Management. Stud Health Technol Inform. 2015; 211: 132-142. 